\title{
Good Agricultural Practices: A Prequisite Approach for Enhancing the Quality of Indian Herbal Medicines
}

\author{
Preet Amol Singh and Ashish Baldi* \\ Department of Pharmaceutical Sciences \& Technology, Maharaja Ranjit Singh Punjab Technical University, India
}

Received: June 13, 2018; Published: June 20, 2018

*Corresponding author: Ashish Baldi, Department of Pharmaceutical Sciences \& Technology, Maharaja Ranjit Singh Punjab Technical University, Bathinda-151001, India, Tel: 91- 8968423848; Email: baldiashish@gmail.com

\begin{abstract}
India is a land where huge population depends upon its ancient system of medicines involving herbs and spices for the treatment of ailments; it is a home for very old system of medicines which continue to be the mainstay of healthcare delivery to a vast segment of society even today. Growth of herbal based healthcare sector in India is putting high demand on both wild collected and cultivated medicinal plants. Unfortunately, because of the poor quality of some herbal medicines, there are number of reports of patients complaining negative consequences caused by the herbal medicines in India. The quality of the herbal medicine is somehow directly related to the quality of raw medicinal plant materials. Therefore, it is prerequisite to follow Good Agricultural and Collection Practices (GACP) for medicinal plants as it is the first step in quality assurance, on which safety and efficacy of herbal medicines directly depends. But despite of such WHO (GACP) guidelines, there is still lack of implementation and documentation of GAP of Indian medicinal plants. In this article, various factors concerning quality of the raw medicinal plant material and the role of GAP \& GACP in achieving high quality herbal medicines will be covered.
\end{abstract}

Keywords: WHO; Good Agricultural Practices; Good Agricultural \&Collection Practices; Medicinal Plants, Standardization

\section{Introduction}

Global and national markets for medicinal plants are growing at a reckless pace and are earning significant profits. India has proved itself of being the epicenter of the trading of botanicals [1]. According to the reports of National Plants Medicinal Board (NMPB) India, India has 1,95,000 domestic herbal industries, 1,34,500 export value (dry Weight in MT), 1,67,500 MT (on dry weight basis) rural household demand, 14910 wastage, making 5,11,910 (Dry wt. in MT) a total annual demand of herbal raw drugs for the year 201415. The trade value of herbal raw drugs, estimated to be consumed in the country during the year 2014-15, works out to around US\$ 1 bn $[2,3]$. In the trade of spices alone, India has emerged as a leading country globally. The report of Spice Board of India concludes that exports of Indian spices have continued to show a remarkable rise in value. During the financial year 2016-17, a total of of 9,47,790 tonnes of spices and spice products valued (US\$2633.30 Million) have been exported from India [3]. As per WHO reports, (65-80\%) of the world's population seek plants or plant-derived natural products for various diseases [4-6]. Over the last decade there has been a revival of herbal drug industry due to irrational use of the chemical drugs, lack of modern curative therapies for treatment of chronic diseases. Historical, religious beliefs and easy availability and affordability are also some of the additional factors supporting promotion of herbal drugs. Many consumers have also turned to herbalism assuming that 'natural means safe' which is true to on basis that herbal medicines can be used up to large extent as compared to purified allopathic medicines but a longer use may cause side effects [7]. From the above data, it can be concluded that most of the population around the world directly or indirectly depends upon the natural resources. Therefore, it is essential to implement GAP \& GACP guidelines to assure the quality of herbal medicines or nutraceuticals. Many countries like European Union, Japan, China, and India have developed their own national guidelines related to good agricultural and collection practices for medicinal plants but there are many factors leading to their poor implementation [8].

GAP and WHO: WHO has a commitment to achieve better health for everyone, everywhere. By the resolution WHA56.31, member states requested the WHO to provide technical support for drafting the guidelines to assure the quality and efficacy of the herbal medicine. WHO developed number of technical guidelines in return to ensure the quality of the herbal medicine out of which GAP and GACP on medicinal plants are the latest $[6,8,9]$. Factors affecting the quality of raw herbal material: There are many factors like genetics, environmental, collection procedures etc. mentioned 
in Fig.1, that are associated with the poor quality of the medicinal plants, furthermore, it is very difficult task to train farmers or to force farmers and other relevant persons involved in the whole process of cultivation, collection, processing to adopt GAP practices [8,9] (Figure 1).

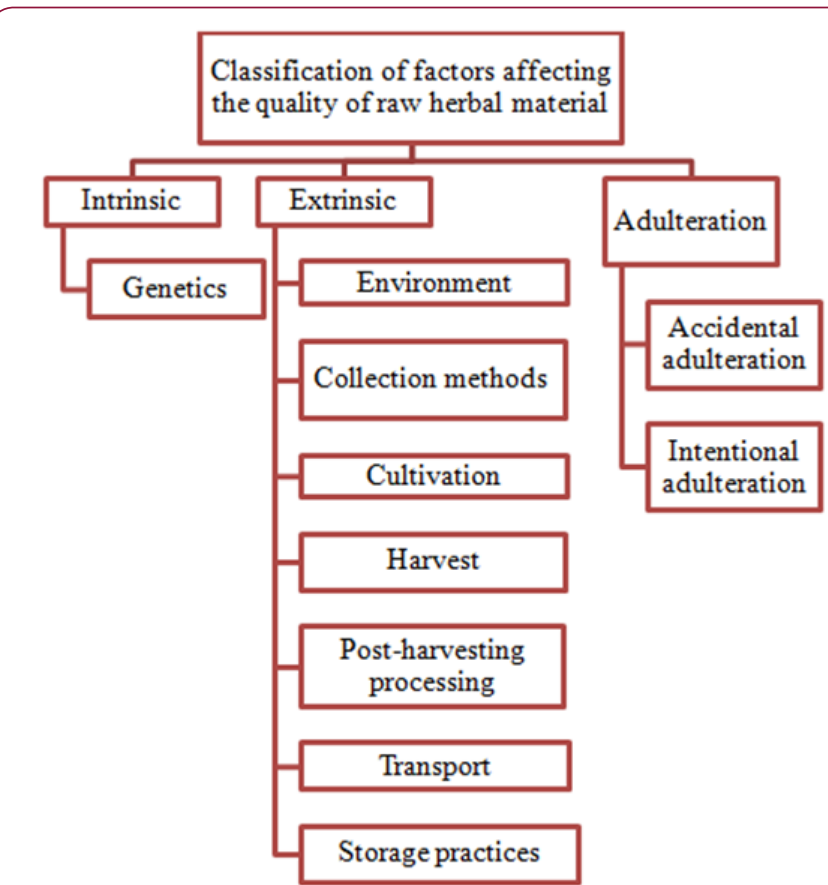

Figure 1: Factors affecting the quality of raw herbal materials.

\section{GAP Guidelines for Medicinal Plants}

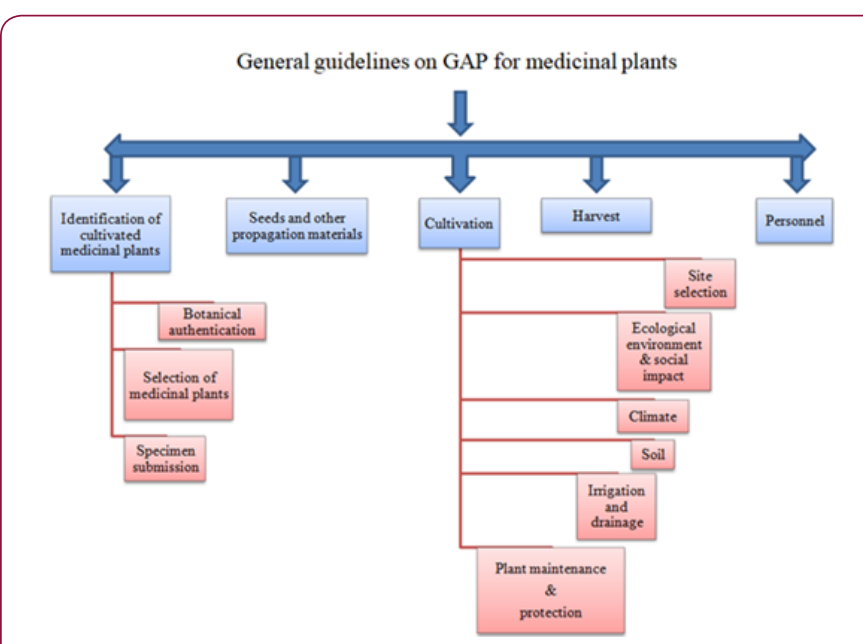

Figure 2: General guidelines on GAP for medicinal plants.

GAP guidelines assure full protection to the plant materials from the factors deteriorating the quality of medicinal plants. Guidelines as proposed by WHO, aims to achieve quality assurance of the herbal medicine by increasing the standards of medicinal plant material right from its cultivation, collection and post harvest operations. WHO GAP and GACP guidelines also intend to guide the formulation of national GAP \& GACP guidelines and aims to prepare monographs of medicinal plants $[8,10]$. It also encourages supporting sustainable cultivation and also promotes conservation of medicinal plants. Implementation of GAP would promote optimum utilization of water resources, pesticides, fertilizers and would provide eco-friendly agriculture. Its social dimension also includes protecting the agricultural workers' health from improper use of chemicals and pesticides [11]. General WHO GAP guidelines for medicinal plants are represented in Figure 2.

\section{General Guidelines for the GACP for the Medicinal Plants}

Good Agriculture and Collection Practices (GACP) ensures to achieve the best collection practices for small and large-scale collection of fresh medicinal plant materials while maintaining long term survival of wild populations and their associated habitats $[8,12]$.It also promotes conservation of endangered medicinal plants. GACP provides suitable collection practices for each medicinal plant species and plant part used (roots, leaves, fruits etc.) [13]. As there are number of regional issues that concerns the collection of medicinal plants, so all these issues should be addressed accordingly before collection of plant part. The general guidelines for the GACP of medicinal plants are represented in Figure 3.

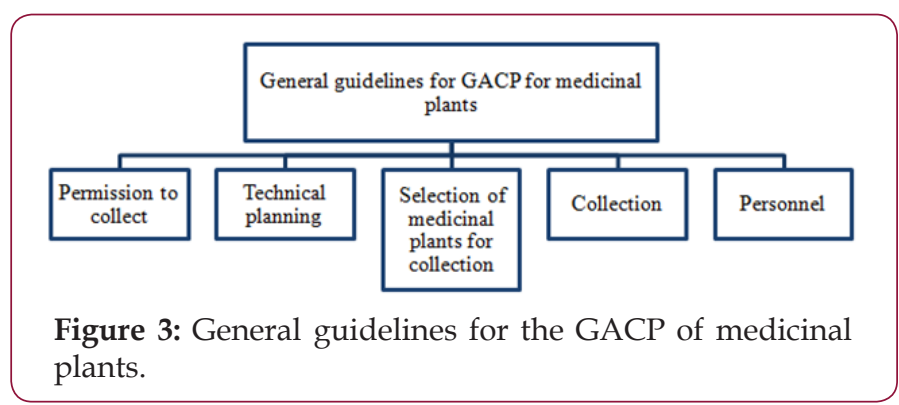

\section{Common Technical Aspects of GAP \& GACP for medicinal Plants}

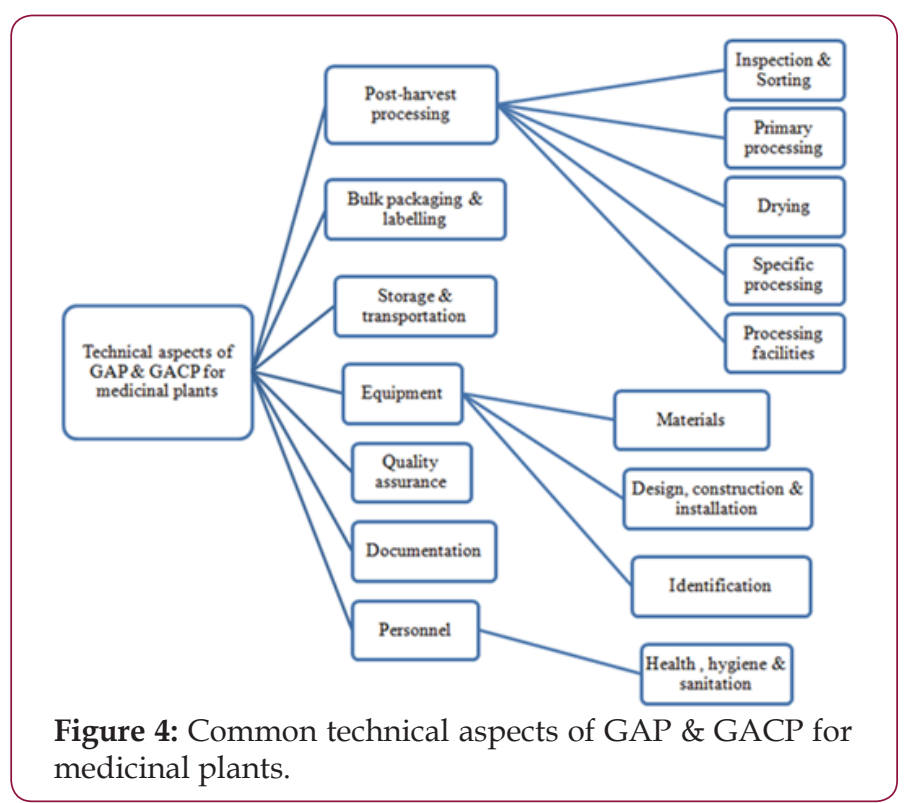

Technical aspects of GAP \& GACP for medicinal plants play a vital role in the quality assurance of the herbal medicines. As mentioned in Figure 4, it covers basic operation like post harvesting 
techniques, storage, transportation, and documentation etc. of medicinal raw materials for their proper utilization in the herbal industries [8,14-16].

\section{Need of Implementing GAP \& GACP on Medicinal Plant Cultivation}

A lot of problems exist on the standardization pattern of herbal medicines because of presence of thousands of secondary metabolites that may participate in your body pharmacologically [17]. Furthermore, there are various minor and major constituents that are prone to degrade if not handled with care e.g. pharmacological active volatile constituents of the plants are degraded when exposed to sunlight, similarly there are many plants that need proper transport conditions for their survival [18]. There are many challenges that concern the quality of the herbal medicine and GAP and GACP is the first step in achieving the quality and efficacy of the herbal medicine. If GAP and GACP is implemented properly half of the problems related to medicinal plants half get solved as it provides systematic review on how to handle medicinal plants. GAP provides us the documented proof on how to handle medicinal plants right from its cultivation to post harvesting operations $[8,9,12]$. At the time when we are surrounded by polluted environment and food, it limits the use of pesticides that are hazardous to both farmer and the consumers [19]. As the world is turning towards herbalism, it is high time to implement GAP and GACP for the medicinal plants as they have direct contact with the consumers health and hence their quality can not be compromised at any level.

\section{Conclusion and Future Recommendations}

More than $70 \%$ of the Indian population depends upon the botanicals directly and indirectly and India has emerged as a second largest country in export of medicinal plants. But still there is lack of awareness amongst the population regarding Good Agriculture and Collection Practices of herbal raw materials. India still lacks behind in developing the monographs on GAP of medicinal plants. Our food chain is prone to become toxic in years as there is over use of pesticides in the field. No proper training is provided to the farmers regarding GAP \& GACP of medicinal plants resulting in over utilization of natural resources. We strongly recommend implementation of GAP and GACP for medicinal plants to ensure the quality assurance of herbal medicines and also increasing the yield of the crop. Implementing GAP \& GACP will eventually result in increasing trade of medicinal plants. It is further proposed to develop of GAP \& GACP monographs of Indian medicinal plants with proper documentation of Indian medicinal plants covering all aspects of cultivation and utilization. With the support of government and local agencies these monographs may be then implemented at grass root level to train farmers for production of quality herbal raw material, which may lead to their financial sustenance and better livelihood.

\section{References}

1. Sharma A, Shanker C, Tyagi LK, Singh M, Rao CV (2008) Herbal medicine for market potential in India: An overview. Academic Journal of Plant Sciences 1(2): 26-36.
2. Goraya GS, Ved DK (2017) Medicinal plants in India: An assessment of their demand and supply. National Medicinal Plants Board, Ministry of AYUSH, Government of India, New-Delhi and Indian Council of Forestry Research \& Education, Dehradun.

3. Spice Board of India, Annual Report 2016-17, Spices Board, Ministry of Commerce \& Industry Government of India (2016-17).

4. Qi Z, Kelley E (2014) The WHO Traditional Medicine Strategy 20142023: A perspective. Science, 346(6216): S5-S6.

5. Van Andel T, Carvalheiro LG (2013) Why urban citizens in developing countries use traditional medicines: the case of Suriname. EvidenceBased Complementary and Alternative Medicine 43: 1-13.

6. Oyebode O, Kandala NB, Chilton PJ, Lilford RJ (2016) Use of traditional medicine in middle-income countries: A WHO-SAGE study. Health Policy and Planning 31(8): 984-991.

7. Singh PA, Desai SD, Singh J (2018) A review on plant antimicrobials of past decade. Current Topics in Medicinal Chemistry.

8. World Health Organization (2003) WHO Guidelines on Good Agricultural and Collection Practices [GACP] for Medicinal Plants. World Health Organization.

9. Harnischfeger G (2000) Proposed guidelines for commercial collection of medicinal plant material. Journal of Herbs, Spices \& Medicinal Plants $7(1): 43-50$.

10.Zhang J, Wider B, Shang H, Li X, Ernst E (2012) Quality of herbal medicines: challenges and solutions. Complementary Therapies in Medicine 20(1-2): 100-106.

11. Lubbe A, Verpoorte R (2011) Cultivation of medicinal and aromatic plants for specialty industrial materials. Industrial Crops and Products 34(1): 785-801.

12. Zhang B, Peng Y, Zhang Z, Liu H, Qi Y, et al. (2010) GAP production of TCM herbs in China. Planta Medica 76(17): 1948-1955.

13. Warude D, Patwardhan B (2005) Botanicals: Quality and regulatory issues.Journal of Scientific \& Industrial Research 64: 83-92.

14. Sahoo N, Manchikanti P (2013) Herbal drug regulation and commercialization: An Indian industry perspective. The Journal of Alternative and Complementary Medicine 19(12): 957-963.

15. Máthé Á, Máthé I (2006) Quality assurance of cultivated and gathered medicinal plants. In XXVII International Horticultural CongressIHC2006: International Symposium on Plants as Food and Medicine: The Utilization 765: 67-76.

16. Singh PA, Brindavanam NB, Kimothi GP, Verma R, Aeri V (2016) A validated HPLC method for the determination of betulin in the stem bark of Tectona grandisLinn. International Journal of Pharmaceutical Sciences and Research 7(2): 719-723.

17. Folashade O, Omoregie H, Ochogu P (2012) Standardization of herbal medicines-A review. International Journal of Biodiversity and Conservation 4(3): 101-112.

18. Maki H, Sasaki T, Harayama S (2001) Photo-oxidation of biodegraded crude oil and toxicity of the photo-oxidized products. Chemosphere 44(5): 1145-1151.

19. Wesseling C, Aragón A, Castillo L, Corriols M, Chaverri F, et al. (2001) Hazardous pesticides in central America. International Journal of Occupational and Environmental Health 7(4): 287-294. 
(c) (P) This work is licensed under Creative Submission Link: https://biomedres.us/submit-manuscript.php

$\begin{array}{ll}\text { BIOMEDICAL } & \text { Assets of Publishing with us } \\ \text { RESEARCHES } & \text { - Global archiving of articles } \\ \text { - Immediate, unrestricted online access } & \text { - Rigorous Peer Review Process } \\ & \text { - Authors Retain Copyrights } \\ \end{array}$

